\title{
Commentary: Invited commentary
}

\author{
Nkosi H. Alvarez, MD, ${ }^{a}$ and T. Sloane Guy, MD, MBA ${ }^{b}$
}

\footnotetext{
From the ${ }^{\mathrm{a}}$ Department of Surgery and ${ }^{\mathrm{b}}$ Division of Cardiovascular Surgery, Thomas Jefferson University, Philadelphia, Pa.

Disclosures: Dr Guy discloses a financial relationship with Edwards Lifesciences, Medtronic, Verb Surgical, and Intuitive Surgical. Dr Alvarez has nothing to disclose with regard to commercial support.

This invited commentary has been copublished in The Annals of Thoracic Surgery and The Journal of Thoracic and Cardiovascular Surgery.

Received for publication June 24, 2019; accepted for publication June 25, 2019; available ahead of print Aug 15, 2019.

Address reprint requests to: T. Sloane Guy, MD, MBA, Division of Cardiovascular Surgery, Thomas Jefferson University, 1015 Walnut St, Curtis Building, Ste 620, Philadelphia, PA 19107 (E-mail: sloane.guy@ jefferson.edu).

J Thorac Cardiovasc Surg 2019;158:1137-8

$0022-5223 / \$ 36.00$

(C) 2019 by The Society of Thoracic Surgeons and The American Association for Thoracic Surgery. Published by Elsevier Inc.

https://doi.org/10.1016/j.jtcvs.2019.06.100
}

Luc and colleagues ${ }^{1}$ report results of the experience of The Thoracic Surgery Social Media Network (TSSMN), a social media collaborative formed in 2015 by The Annals of Thoracic Surgery and The Journal of Thoracic and Cardiovascular Surgery. Using the Twitter handle @TSSMN and hashtag \#TSSMN, the authors show that since its inception, \#TSSMN has generated 17,181 total tweets, 2,100 users, and 32,226,280 impressions. ${ }^{1}$ In addition, thirteen 1-hour TweetChats, involving global leaders in the cardiothoracic community, drew 489 participants, 5195 total tweets, and 17,297,708 total impressions. As such, the authors demonstrate that the online community generated around @TSSMN and \#TSSMN enhances the ability of the journals to connect with their readership and should be commended for their detailed report.

Critical to the success of TSSMN were the use of delegates representing a range of cardiothoracic subspecialties with broad geographic representation. With a combined following of 52,983 users, TSSMN delegates were able engaging wide-ranging discussion through broad engagement with the social media community. Furthermore, use of featured articles that were open access likely allowed for much broader participation in discussion by allowing universal access regardless of financial or geographic background. Given social media's permanence and widespread reach, the journals' push to provide a channel for open-access, transparent, and critical appraisal from end users may, arguably, make social media forums the best avenues for postpublication peer review while expanding perspectives and leading to collaboration.

Although the content of the article is not traditionally thought of as "science," the scientific focus of any to widely disseminate new, original journal articles while

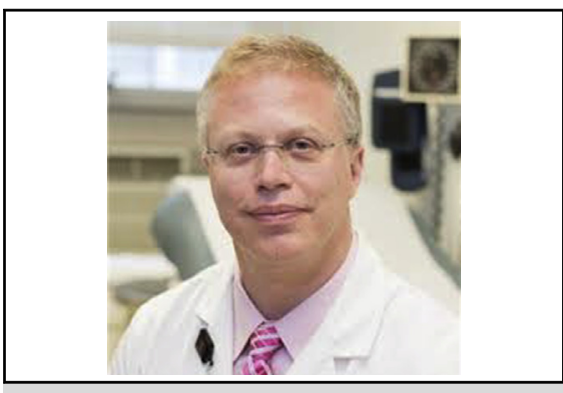

T. Sloane Guy, MD, MBA

Central Message

The Thoracic Surgery Social Media Network (TSSMN) has resulted in the improved dissemination of thoracic surgery information via the use of social media networks. Such connections will be increasingly important in connecting journals to their readership.

See Article page 1127. journal should be to study anything that affects care, and social media is of major importance in the dissemination of medical information today. With more than 2246 followers and a new follower accumulation of 45 users a month, the authors have demonstrated TSSMN's ability to foster a forum that guides journal and information growth.

Recent studies showing the positive correlation of journal Twitter activity to impact factor ${ }^{2}$ and correlation between social media and citation rates ${ }^{3}$ lend support to the continued active presence of journals on Twitter. In addition, with the help of advocacy groups, the journals' online presence and the online presence of leaders in the field can be used to help stymie or correct medical misinformation propagation ${ }^{4,5}$ while improving patient care and changing the perception of surgery as cryptic or esoteric.

One notable limitation of the study, however, is the inability to differentiate whether social media attention, generated in the form of tweet impressions, followers, or other social media metrics, represented negative or positive attention. More research is needed to better define social media attention with article reads, article-level metrics, citations, and journal impact factor. Albeit, while the authors have shown TSSMN is uniquely placed, expansion to other social media platforms will allow the journals to further influence information, education, and collaboration paradigms into the future. 


\section{References}

1. Luc JGY, Ouzounian M, Bender EM, Blitz A, Stamp NL, Varghese TK Jr, et al. The Thoracic Surgery Social Media Network: early experience and lessons learned. J Thorac Cardiovasc Surg. 2019;158:1127-36.

2. Hughes H, Hughes A, Murphy C. The use of Twitter by the trauma and orthopaedic surgery journals: twitter activity, impact factor, and alternative metrics. Cureus. 2017;9:e1931.
3. Lamb CT, Gilbert SL, Ford AT. Tweet success? Scientific communication correlates with increased citations in Ecology and Conservation. PeerJ. 2018;6: e4564.

4. Armstrong PW, Naylor CD. Counteracting health misinformation: a role for medical journals? JAMA. 2019;321:1863-4.

5. Chou WS, Oh A, Klein WMP. Addressing health-related misinformation on social media. JAMA. 2018;320:2417-8. 